\title{
Infections of respiratory or abdominal origin in ICU patients: what are the differences?
}

\author{
Elena Volakli', Claudia Spies ${ }^{2}$, Argyris Michalopoulos ${ }^{3}$, AB Johan Groeneveld ${ }^{4}$, Yasser Sakr ${ }^{5}$, Jean-Louis Vincent ${ }^{*}$
}

\begin{abstract}
Introduction: There are few data related to the effects of different sources of infection on outcome. We used the Sepsis Occurrence in Acutely ill Patients (SOAP) database to investigate differences in the impact of respiratory tract and abdominal sites of infection on organ failure and survival.

Methods: The SOAP study was a cohort, multicenter, observational study which included data from all adult patients admitted to one of 198 participating intensive care units (ICUs) from 24 European countries during the study period. In this substudy, patients were divided into two groups depending on whether, on admission, they had abdominal infection but no respiratory infection or respiratory infection but no abdominal infection. The two groups were compared with respect to patient and infection-related characteristics, organ failure patterns, and outcomes.

Results: Of the 3,147 patients in the SOAP database, 777 (25\%) patients had sepsis on ICU admission; 162 (21\%) had abdominal infection without concurrent respiratory infection and 380 (49\%) had respiratory infection without concurrent abdominal infection. Age, sex, and severity scores were similar in the two groups. On admission, septic shock was more common in patients with abdominal infection $(40.1 \%$ vs. $29.5 \%, P=0.016)$ who were also more likely to have early coagulation failure $(17.3 \%$ vs. $9.5 \%, P=0.01)$ and acute renal failure $(38.3 \%$ vs. $29.5 \%, P=0.045)$. In contrast, patients with respiratory infection were more likely to have early neurological failure (30.5\% vs. 9.9\%, $P<0.001)$. The median length of ICU stay was the same in the two groups, but the median length of hospital stay was longer in patients with abdominal than in those with respiratory infection ( 27 vs. 20 days, $P=0.02$ ). ICU (29\%) and hospital (38\%) mortality rates were identical in the two groups.

Conclusions: There are important differences in patient profiles related to the site of infection; however, mortality rates in these two groups of patients are identical.
\end{abstract}

\section{Introduction}

Infection is a major challenge in the intensive care unit (ICU). Cited prevalence rates of ICU infection vary between $45 \%$ to $58 \%[1,2]$, and incidence rates between $30 \%$ to $35 \%[3,4]$. Infections are already present on admission to the ICU in about $50 \%$ of cases; rates are perhaps even higher in studies limited to critically ill patients [1-6].

It has been shown that infections originating from the urinary tract usually have a better outcome than infections from other sources [7-10]. However, whether there are differences in outcomes for other sources of sepsis is not well defined. Lung and abdominal infections are the

\footnotetext{
* Correspondence: jlvincen@ulb.ac.be

'Dept of Intensive Care, Erasme Hospital, Université Libre de Bruxelles, Route de lennik 808, 1070 Brussels, Belgium
}

most common infections in the ICU $[3,4,6,11]$, and several studies have suggested that, although respiratory infections are more common, abdominal infections may be more severe $[3,10,12-15]$. However, whether this translates into worse outcomes is unclear. Importantly, if outcomes vary according to the source of infection, this may impact on clinical trial design, as currently patients with infections from different sources are often grouped together.

The aim of the present study was, therefore, to investigate whether the presence at ICU admission of infections originating in these two sites, abdomen and lung, had any impact on patterns of organ failure or on patient outcome. For this purpose, we used the database of the Sepsis Occurrence in Acutely Ill Patients (SOAP) 
study [6], a large systematic cohort study performed in European ICU patients.

\section{Materials and methods Study design}

The SOAP study was a prospective multicenter observational study designed to evaluate the epidemiology and characteristics of sepsis in European countries and was initiated by a working group of the European Society of Intensive Care Medicine. Full details of recruitment, data collection and management have been provided elsewhere [6]. Briefly, all adult patients (> 15 years old) admitted to a participating center (see Additional file 1 for a list of participating countries and centers) between 1 and 15 May 2002 were included, except patients who stayed in the ICU for less than 24 hours for routine postoperative surveillance. Due to the observational character of the study which did not require any deviation from routine medical care, institutional review board approval was either waived or expedited in participating institutions and informed consent was not required. Patients were followed up until death, hospital discharge, or for 60 days.

\section{Data collection and management}

Data were collected prospectively using pre-printed case report forms and entered centrally by medical personnel. Data collection on ICU admission included demographic data, comorbid diseases, admission category, source of admission and admission diagnosis. Clinical and laboratory data needed to calculate the Simplified Acute Physiology Score II (SAPS II) were reported as the worst value within 24 hours after hospital admission [16]. Evaluation of organ function was made using the Sequential Organ Failure Assessment (SOFA) score, based on the most abnormal value for each of the six organ systems [17]. Daily collection of data included infection characteristics, organ function and the need for special supportive modalities such as mechanical ventilation, hemofiltration and hemodialysis.

\section{Definitions}

Infection was defined as the presence of a pathogenic microorganism in a sterile milieu and/or clinically suspected infection, plus the administration of antibiotics. Clinically suspected infection was diagnosed at the discretion of the attending physician. Sepsis and severe sepsis and septic shock were defined by standard criteria [18]. Organ failure was defined as a Sequential Organ Failure Assessment (SOFA) score $>2$ for the organ in question [17]. Early organ failure and late organ failure were defined as those occurring within and after 48 hours of a diagnosis of sepsis, respectively. For the purposes of this substudy, two groups were identified:
Patients with abdominal infection (microbiologically proven or clinical diagnosis) on admission to the ICU without any concurrent respiratory infection and those with respiratory infections (microbiologically proven or clinical diagnosis) on ICU admission without concurrent abdominal infection. Secondary infections were defined as infections occurring more than 24 hours after onset of a preexisting infection, at a site other than the abdominal or respiratory system for patients in the abdominal or respiratory groups, respectively.

\section{Statistical analysis}

Data were analyzed using the Statistical Package for Social Sciences (SPSS) for Windows, version 17.0 (SPSS Inc., Chicago, IL, USA). A Kolmogorov-Smirnov test was used, and histograms and normal-quantile plots were examined to verify the normality of distribution of continuous variables. Discrete variables are expressed as counts (percentage) and continuous variables as means $\pm \mathrm{SD}$ or median $\left(25^{\text {th }}\right.$ to $75^{\text {th }}$ percentiles). For demographic and clinical characteristics of the study groups, differences between groups were assessed using a chisquare, Fisher's exact test, Student's t-test or MannWhitney U test, as appropriate. We performed a multivariate logistic regression analysis with development of secondary infection as the dependent factor to investigate the influence of length of ICU stay on the development of secondary infection in abdominal and respiratory groups. Variables considered for the analysis included, demographic data, co-morbidities, SAPS II score on admission, type of microorganism, organ failure assessed by the SOFA score. Only variables associated with a higher risk of development of secondary infection $(P<0.2)$ on a univariate basis were modeled. All variables included in the model were tested for colinearity. Interaction terms involving combinations between length of ICU stay and presence in the abdominal or respiratory group were tested. A Hosmer and Lemeshow goodness of fit test was performed and odds ratios and their corresponding 95\% confidence intervals were calculated [19]. We also performed a multivariate Cox proportional hazard model with time to in-hospital death as the dependent factor. Variables included in the Cox regression analysis were: age, gender, comorbid diseases, SAPS II and SOFA scores on admission, the type of admission (medical or surgical), source of admission, admission diagnosis, the presence of sepsis, early organ failure, and the need for mechanical ventilation or renal replacement therapy during the ICU stay. Variables were introduced in the model if significantly associated with a higher risk of in-hospital death on a univariate basis at a $P$-value $<0.2$. Colinearity between variables was excluded prior to modeling. The time dependent covariate method was used to check the proportional 
hazard assumption of the model; an extended Cox model was constructed, adding interaction terms that involve time, that is, time dependent variables, computed as the by-product of time and individual covariates in the model (time $\times$ covariate). Individual timedependent covariates were introduced one by one and in combinations in the extended model, none of which was found to be significant. A stepwise approach was used and presence in the abdominal or respiratory group variable was forced as the last step in the model. A Kaplan-Meier survival analysis was performed and survival between groups was compared using a Log rank Test. All statistics were two-tailed and a $P<0.05$ was considered to be statistically significant.

\section{Results}

\section{Study population}

Of the 3,147 patients enrolled in the SOAP study, 777 (25\%) had sepsis on admission to the ICU; of these, 162 (21\%) had abdominal infection without concurrent respiratory infection and $380(49 \%)$ had respiratory infection without concurrent abdominal infection. The baseline characteristics of the patients are summarized in Table 1. Age, sex, SAPS II and SOFA scores were similar in the two groups. Patients with abdominal infections were more likely to be surgical admissions and to have been referred from the operating room or recovery room; they were more likely than patients with respiratory infections to have cancer but less likely to have chronic obstructive pulmonary disease (COPD) or hematologic cancer. Patients with respiratory infection were admitted mainly because of respiratory (57\%), cardiovascular (19\%) and neurologic diagnoses (13\%), while patients with abdominal infection were primarily admitted because of digestive/liver (40\%) and cardiovascular diagnoses (34\%).

\section{Infection-related characteristics}

Table 2 shows the major microbiological data. Microbiologic cultures were positive in $46 \%$ of the patients. Diagnostic criteria for infection and the overall rates of Gram-positive, Gram-negative, or fungal infection were similar in the two groups. The most commonly isolated organisms in patients with abdominal infections were Staphylococcus aureus and Streptococcus group D, and in patients with respiratory infections, the most commonly isolated organisms were S. aureus and Pseudomonas species. Streptococcus pneumoniae infections were more common in patients with respiratory than in those with abdominal infections $(4.7 \%$ vs. $0.6 \%, P=0.02)$, while Streptococcus group D $(18.5 \%$ vs. $6.3 \%, P<0.001)$ and any streptococcal $(24.1 \%$ vs. $12.9 \%, P<0.001)$ infections were more common in patients with abdominal infections. Escherichia coli $(15.4 \%$ vs. $7.6 \%, P=0.006)$ and Candida non-albicans (6.2\% vs. $2.4 \%, P=0.027)$ infections were also more common in patients with abdominal infections than in those with respiratory infections.

Secondary infections were more common in patients with abdominal infections (70 patients, $43 \%$ ), than in those with respiratory infections (119 patients, 31\%), $P=0.010$. Thirty-five patients $(22 \%)$ with abdominal infections developed respiratory infections later during the ICU stay and 15 patients (4\%) with respiratory infections developed abdominal infections (Table 3). Patients with abdominal infection on admission were more likely to develop secondary skin/wound infection (16\% vs. $5.5 \%, P<0.001)$ whereas patients with respiratory infections were more likely to develop secondary urinary infections $(9.2 \%$ vs. $1.9 \%, P<0.001)$. Patients in the abdominal group who developed secondary infections had a longer ICU stay than those who did not (12 (5.7 to 27.3) days versus 9.8 (4.6 to 21.9), $P<0.05$ ). Multiple logistic regression analysis showed that the relationship between the abdominal group and the development of secondary infection was related to ICU stay (interaction parameter $=0.069, P=0.011$ (Table 4). Specifically, the odds ratio of developing secondary infections increased with increasing duration of ICU stay in the abdominal group (Figure 1).

\section{Morbidity and mortality}

Although the incidence of severe sepsis on admission was similar in the two groups (around $70 \%$ ), more patients with abdominal infection had septic shock on admission than patients with respiratory infection (40.1\% vs. $29.5 \%, P=0.016)$. However, when considering the incidence of sepsis syndromes during the whole ICU stay, these differences lost statistical significance (Table 5).

Patients with abdominal infection also had a greater incidence of early coagulation failure $(17.3 \%$ vs. $9.5 \%$, $P=0.01)$ and early acute renal failure $(38.3 \%$ vs. $29.5 \%$, $P=0.04)$, and more needed hemofiltration than patients with respiratory infection. Patients with respiratory infection were more likely to have early neurological failure than patients with abdominal infection $(30.5 \%$ vs. $9.9 \%, P<0.001$ ).

The median duration of ICU stay was the same in the two groups, but the median duration of hospital stay was longer for patients with abdominal infection (27 days vs. 20 days, $P=0.02)$. ICU $(29.0 \%$ vs. $28.9 \%)$ and hospital (37.5\% vs. $38.1 \%)$ mortality rates were remarkably similar in the two groups of patients. In a Kaplan Meier survival analysis, 60-day survival was similar between groups (Log Rank $=0.267, P=0.605$; Figure 2). In Cox regression analysis (Table 6), age, cancer, septic shock on admission, early coagulation failure, acute 
Table 1 Baseline characteristics and outcomes

\begin{tabular}{|c|c|c|c|c|}
\hline Characteristic & $\begin{array}{l}\text { All patients } \\
(\mathrm{n}=542)\end{array}$ & $\begin{array}{l}\text { Abdominal infection } \\
(n=162)\end{array}$ & $\begin{array}{l}\text { Respiratory infection } \\
(n=380)\end{array}$ & $P$-value \\
\hline Age, years & $63.2 \pm 15.7$ & $65.1 \pm 15.0$ & $62.4 \pm 16.0$ & 0.11 \\
\hline Male & $314(58.4 \%)$ & $89(55.3 \%)$ & $225(59.7 \%)$ & 0.34 \\
\hline SAPS II score & $43.6 \pm 17.1$ & $43.1 \pm 17.7$ & $43.9 \pm 16.8$ & 0.42 \\
\hline SOFA score & $6.5 \pm 4.1$ & $6.4 \pm 4.0$ & $6.6 \pm 4.2$ & 0.65 \\
\hline \multicolumn{5}{|l|}{ Co-morbidities } \\
\hline Cancer & 79 (14.6\%) & $34(21.0 \%)$ & $45(11.8 \%)$ & 0.006 \\
\hline Hematologic cancer & $26(4.8 \%)$ & $2(1.2 \%)$ & $24(6.3 \%)$ & 0.01 \\
\hline COPD & 107 (19.7\%) & $19(11.7 \%)$ & $88(23.2 \%)$ & 0.002 \\
\hline Cirrhosis & $26(4.8 \%)$ & $10(6.2 \%)$ & $16(4.2 \%)$ & 0.32 \\
\hline HIV and/or AIDS & $7(1.3 \%)$ & 0 & $7(1.8 \%)$ & 0.10 \\
\hline Heart failure & $42(7.7 \%)$ & $8(4.9 \%)$ & 34 (8.9\%) & 0.11 \\
\hline Diabetes & $35(6.5 \%)$ & $9(5.6 \%)$ & $26(6.8 \%)$ & 0.57 \\
\hline \multicolumn{5}{|l|}{ Admission category } \\
\hline Medical & $333(61.4 \%)$ & $32(19.8 \%)$ & $301(79.2 \%)$ & $<0.001$ \\
\hline Surgical & $209(38.6 \%)$ & $130(80.2 \%)$ & 79 (20.8\%) & $<0.001$ \\
\hline Elective & $82(15.1 \%)$ & $35(21.6 \%)$ & 47 (12.4\%) & \\
\hline Emergency & $127(23.4 \%)$ & $95(58.6 \%)$ & 32 (8.4\%) & \\
\hline Source of admission & & & & $<0.001$ \\
\hline ER/Ambulance & $118(24.0 \%)$ & $17(11.6 \%)$ & $101(29.3 \%)$ & \\
\hline Hospital floor & $191(38.9 \%)$ & $40(27.4 \%)$ & $151(43.8 \%)$ & \\
\hline OR/Recovery & $126(25.7 \%)$ & $82(56.2 \%)$ & $44(12.8 \%)$ & \\
\hline Hospital other & $56(11.4 \%)$ & 7 (4.8\%) & 49 (14.2\%) & \\
\hline Admission diagnosis & & & & $<0.001$ \\
\hline Monitoring & $15(2.8 \%)$ & $7(4.5 \%)$ & $8(2.1 \%)$ & \\
\hline Neurologic & $51(9.5 \%)$ & $3(1.9 \%)$ & $48(12.7 \%)$ & \\
\hline Respiratory & $229(42.8 \%)$ & $15(9.6 \%)$ & $214(56.6 \%)$ & \\
\hline Cardiovascular & $123(23.0 \%)$ & $53(33.8 \%)$ & $70(18.5 \%)$ & \\
\hline Renal & $14(2.6 \%)$ & $9(5.7 \%)$ & $5(1.3 \%)$ & \\
\hline Digestive/liver & $73(13.6 \%)$ & $63(40.1 \%)$ & $10(2.6 \%)$ & \\
\hline Trauma & $16(3.0 \%)$ & $4(2.5 \%)$ & $12(3.2 \%)$ & \\
\hline Others & $14(2.7 \%)$ & $3(2.0 \%)$ & $11(2.9 \%)$ & \\
\hline \multicolumn{5}{|l|}{ Sepsis syndromes } \\
\hline Severe sepsis & $391(72.1 \%)$ & $113(69.8 \%)$ & $278(73.2 \%)$ & 0.41 \\
\hline Septic shock & $177(32.7 \%)$ & $65(40.1 \%)$ & $112(29.5 \%)$ & 0.01 \\
\hline Length of ICU stay (days) & $6(3-13)$ & $6(2-15)$ & $6(3-13)$ & 0.95 \\
\hline Length of hospital stay (days) & $21(10-44)$ & $27(13-48)$ & $20(10-41)$ & 0.02 \\
\hline ICU mortality & $157(29.0 \%)$ & 47 (29.0\%) & $110(28.9 \%)$ & 0.98 \\
\hline Hospital mortality & $204(37.6 \%)$ & $60(37.5 \%)$ & $144(38.1 \%)$ & 0.89 \\
\hline
\end{tabular}

Data are expressed as mean \pm standard deviation, number (percentage), or median (interquartile range). AIDS: acquired immune deficiency syndrome; COPD: chronic obstructive pulmonary disease; ER: emergency room; HIV: human immunodeficiency virus; ICU: intensive care unit; OR: operating room; SAPS II: Simplified Acute Physiology Score; SOFA: Sequential Organ Failure Assessment

renal failure, and neurological failure were all associated with an increased risk of death, but abdominal or respiratory infection were not.

\section{Discussion}

Using data from a large, prospective, pan-European database, we investigated the impact on organ failure and survival of the presence on admission of infection at two of the most common sites, the lung and the abdomen. On admission, patients with abdominal infection were more likely to have septic shock, early coagulation failure and early acute renal failure, and more needed hemofiltration than patients with respiratory infection. In contrast, patients with respiratory infections were more likely to have concurrent early neurological dysfunction than patients with abdominal infection. 
Table 2 Diagnostic criteria for infection and the microorganisms isolated in patients with abdominal and respiratory infections

\begin{tabular}{|c|c|c|c|c|}
\hline Characteristic & $\begin{array}{l}\text { All patients } \\
(\mathrm{n}=542)\end{array}$ & $\begin{array}{l}\text { Abdominal infection } \\
\qquad(n=162)\end{array}$ & $\begin{array}{l}\text { Respiratory infection } \\
\qquad(n=380)\end{array}$ & $P$-value \\
\hline \multicolumn{5}{|l|}{ Diagnostic criteria } \\
\hline Isolates only & $44(8.1 \%)$ & $9(5.6 \%)$ & 35 (9.2\%) & 0.17 \\
\hline Clinical only & $294(54.2 \%)$ & $91(56.2 \%)$ & $203(53.4 \%)$ & 0.57 \\
\hline Both & $204(37.6 \%)$ & $62(38.3 \%)$ & $142(37.4 \%)$ & 0.85 \\
\hline \multicolumn{5}{|l|}{ Class/microorganism } \\
\hline Gram-positive & $130(23.9 \%)$ & $42(25.9 \%)$ & $88(23.2 \%)$ & 0.58 \\
\hline Gram-negative & $144(26.5 \%)$ & $43(26.5 \%)$ & $101(26.6 \%)$ & 0.64 \\
\hline Anaerobes & $9(1.6 \%)$ & $7(4.3 \%)$ & $2(0.5 \%)$ & 0.45 \\
\hline Atypical microorganisms & $4(0.7 \%)$ & 0 & $4(1.1 \%)$ & 0.323 \\
\hline Fungi & $81(14.9 \%)$ & $30(18.5 \%)$ & $51(13.4 \%)$ & 0.148 \\
\hline \multicolumn{5}{|l|}{ Gram-positive } \\
\hline Any Staphylococcus & $119(22.0 \%)$ & $36(22.2 \%)$ & $83(21.8 \%)$ & 0.92 \\
\hline Staphylococcus aureus & $91(16.8 \%)$ & $30(18.5 \%)$ & $61(16.1 \%)$ & 0.48 \\
\hline MRSA & 59 (10.9\%) & $22(13.6 \%)$ & 37 (9.7\%) & 0.18 \\
\hline Staphylococcus, others & $70(12.9 \%)$ & $19(11.7 \%)$ & $51(13.4 \%)$ & 0.59 \\
\hline Any Streptococcus & $88(16.2 \%)$ & $39(24.1 \%)$ & $49(12.9 \%)$ & $<0.001$ \\
\hline Streptococcus group D & $54(10.0 \%)$ & $30(18.5 \%)$ & $24(6.3 \%)$ & $<0.001$ \\
\hline Streptococcus pneumoniae & $19(3.5 \%)$ & $1(0.6 \%)$ & $18(4.7 \%)$ & 0.02 \\
\hline Streptococcus, others & $19(3.5 \%)$ & $9(5.6 \%)$ & $10(2.6 \%)$ & 0.09 \\
\hline Gram-positive bacilli & $15(2.8 \%)$ & $3(1.9 \%)$ & $12(3.2 \%)$ & 0.57 \\
\hline Gram-positive, others & $10(1.8 \%)$ & $1(0.6 \%)$ & $9(2.4 \%)$ & 0.29 \\
\hline \multicolumn{5}{|l|}{ Gram-negative } \\
\hline Pseudomonas species & $67(12.4 \%)$ & $19(11.7 \%)$ & $48(12.6 \%)$ & 0.77 \\
\hline Escherichia coli & $54(10.0 \%)$ & $25(15.4 \%)$ & $29(7.6 \%)$ & 0.006 \\
\hline Enterobacter & $25(4.6 \%)$ & $11(6.8 \%)$ & $14(3.7 \%)$ & 0.11 \\
\hline Klebsiella & $25(4.6 \%)$ & $6(3.7 \%)$ & $19(5.0 \%)$ & 0.51 \\
\hline Proteus & $15(2.8 \%)$ & $6(3.7 \%)$ & $9(2.4 \%)$ & 0.38 \\
\hline Acinetobacter & $17(3.1 \%)$ & $2(1.2 \%)$ & $15(3.9 \%)$ & 0.11 \\
\hline Haemophilus & $12(2.2 \%)$ & $1(0.6 \%)$ & $11(2.9 \%)$ & 0.12 \\
\hline Gram-negative bacilli & $36(6.6 \%)$ & $12(7.4 \%)$ & $24(6.3 \%)$ & 0.64 \\
\hline Gram-negative, others & $90(16.6 \%)$ & $26(16.0 \%)$ & $64(16.8)$ & 0.82 \\
\hline \multicolumn{5}{|l|}{ Fungi } \\
\hline Candida albicans & $61(11.3 \%)$ & $21(13.0 \%)$ & $40(10.5 \%)$ & 0.41 \\
\hline Candida, others & $19(3.5 \%)$ & $10(6.2 \%)$ & 9 (2.4\%) & 0.02 \\
\hline Fungi, others & $7(1.3 \%)$ & $2(1.2 \%)$ & $5(1.3 \%)$ & 1 \\
\hline Viral/parasitic & $9(1.7 \%)$ & $1(0.6 \%)$ & $8(2.1 \%)$ & 0.21 \\
\hline
\end{tabular}

CSF: cerebrospinal fluid; MRSA: methicillin-resistant S. aureus; Staphylococcus, others includes methicillin-sensitive S. aureus and Staphylococcus coagulase negative methicillin-sensitive; Streptococcus, others includes Streptococcus A, B, C, G group and others; Gram-positive bacilli includes, Moraxella and others; Gram-negative, others includes Salmonella, Serratia, Citrobacter, Stenotrophomonas maltophilia, Campylobacter, other enterobacteroids, Gram-negative cocci; Anaerobes includes Clostridium, Bacteroides, anaerobic cocci, and others; Atypical microorganisms includes Mycobacteria, Chlamydia, Rickettsia, Legionella pneumonia; Fungi, others includes Aspergillus and others. The microorganism was considered once per patient even if present in more than one site.

However, the median length of ICU stay was the same in the two groups and the two groups had identical ICU and hospital mortality rates.

The present study focused on infections originating from the lungs and the abdomen, because these two sites represent the most common causes of infection in acutely ill patients $[3,4,6,11]$, and are also associated with higher workload and increased costs compared to other infections [20]. On admission, $49 \%$ of patients with sepsis had respiratory infections and $21 \%$ abdominal; overall in the SOAP study, $68 \%$ of patients had respiratory and $22 \%$ abdominal infections [6]. Similarly, in a study of 5,878 patients from Australia and New Zealand, the site of infection was pulmonary in $50 \%$ and abdominal in $19 \%$ of the episodes [11]. In another European study of 14,364 patients, the lung contributed to $62 \%$ of infections and intra-abdominal infections to $15 \%$ [3]. 
Table 3 Type of secondary infections

\begin{tabular}{lccc}
\hline & Abdominal infection & Respiratory infection & $\begin{array}{c}\boldsymbol{P} \text { - } \\
\text { value }\end{array}$ \\
\hline Respiratory & $35(21.6 \%)$ & $\mathrm{NA}$ & - \\
Abdominal & $\mathrm{NA}$ & $15(3.9 \%)$ & - \\
Skin/wound & $26(16.0 \%)$ & $21(5.5 \%)$ & $<0.001$ \\
Other & $15(9.3 \%)$ & $27(7.1 \%)$ & 0.39 \\
Unknown & $4(2.5 \%)$ & $5(1.3 \%)$ & 0.46 \\
Bloodstream & $28(17.3 \%)$ & $48(12.6 \%)$ & 0.15 \\
Urinary & $3(1.9 \%)$ & $35(9.2 \%)$ & $<0.001$ \\
Catheter & $14(8.6 \%)$ & $20(5.3 \%)$ & 0.14 \\
CSF & 0 & $2(0.5 \%)$ & 1 \\
\hline
\end{tabular}

NA: not applicable

Although respiratory infections are more common, several studies have suggested that abdominal infections may be more severe $[3,10,12-15]$. The present study supports these findings, as more patients with abdominal infections than with respiratory infections had septic shock on admission. Nevertheless, mortality rates were similar in patients with abdominal and those with respiratory infections. The association between respiratory infection and a higher incidence of early neurological failure may be because respiratory infections are more common in patients with altered mental status or neurological diagnoses [21-23]; in our study, there was a higher proportion of neurological diagnoses in patients with respiratory infections than in those with abdominal infections. Moreover, although the assumed Glasgow coma score is supposed to be used for the SOFA score, it is possible that neurological dysfunction may have been overestimated in sedated patients. The association between abdominal infections and coagulation failure may be related to the fact that more patients with abdominal infections had septic shock, which frequently provokes coagulation abnormalities [24], or by the fact that most of these patients were postoperative, as surgery may be associated with altered coagulation $[25,26]$. However, all these suggestions remain speculative as our study design does not allow us to determine the reasons underlying these associations.

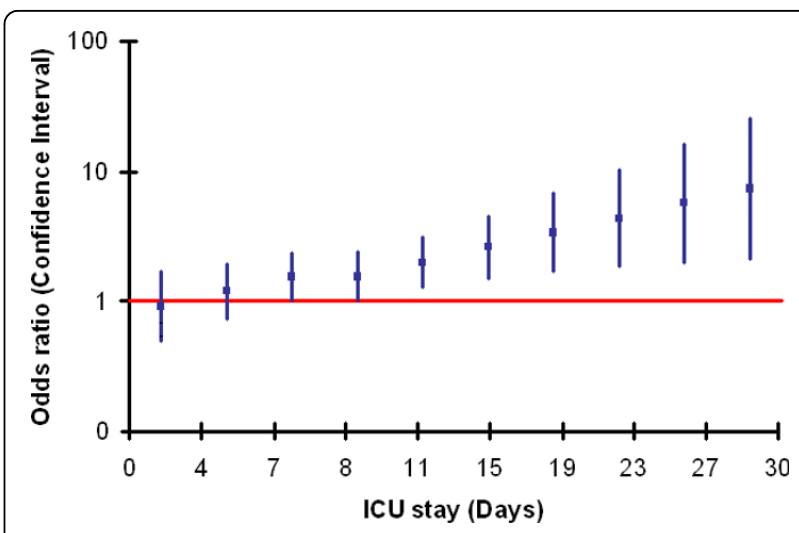

Figure 1 The odds ratios of developing secondary infection in the abdominal group for different durations of ICU stay. The solid line represents the point of significance; ICU stays longer than seven days were associated with a significant risk of developing secondary infection.

It has been fairly consistently reported that secondary infections are more frequent among patients who are already infected when admitted to the ICU, but differences in definitions make it difficult to compare studies $[3,4,13,27,28]$. Alberti et al. [3] reported that $26 \%$ of patients who were infected on ICU admission developed secondary infections compared to $15 \%$ of patients not infected on admission. Malacarne et al. [4] reported that $23 \%$ of patients admitted with infections developed secondary infections compared to $9 \%$ of those who were admitted without infection. Agarwal et al. reported that infection on admission was an independent risk factor for developing an ICU-acquired infection [27]. However, the above studies focused on patients admitted with any infection without distinguishing the type. In our study, secondary infections occurred more commonly in patients admitted with abdominal than with respiratory infection, related to their longer ICU stay as shown by the multivariate analysis. These patients also had a higher incidence of skin/wound infections compared to respiratory patients, likely related to more surgical wound infections. Merlino et al. [28], in a retrospective study of 168 patients with serious intra-abdominal infections, reported that 66 patients $(40 \%)$ developed a

Table 4 Multiple logistic regression analysis in patients with abdominal infections. The development of secondary infection was the dependent variable

\begin{tabular}{|c|c|c|c|c|}
\hline & Estimated coefficient & SD & Odds ratio $(95 \% \mathrm{Cl})$ & $P$-value \\
\hline SAPS II score, per point & 0.016 & 0.006 & $1.016(1.005$ to 1.028$)$ & 0.005 \\
\hline ICU length of stay, per day & 0.055 & 0.011 & $1.057(1.034$ to 1.079$)$ & $<0.001$ \\
\hline \multicolumn{5}{|l|}{ Abdominal/respiratory variable } \\
\hline Respiratory infection & \multicolumn{4}{|c|}{ Reference } \\
\hline Abdominal infection & -0.076 & 0.316 & $0.927(0.499$ to 1.721$)$ & 0.810 \\
\hline Abdominal/respiratory infection by ICU LOS & 0.069 & 0.027 & $1.071(1.016$ to 1.129$)$ & 0.011 \\
\hline
\end{tabular}

$\mathrm{Cl}$ : confidence interval; SD: standard error of the estimate; Hosmer and Lemeshow Chi square 7.636, $P=0.470$. The percentage of correct classifications is 71.4 . 
Table 5 Organ dysfunction patterns

\begin{tabular}{|c|c|c|c|c|}
\hline Characteristic & $\begin{array}{l}\text { All patients } \\
(\mathrm{n}=542)\end{array}$ & $\begin{array}{l}\text { Abdominal infection } \\
\qquad(n=162)\end{array}$ & $\begin{array}{l}\text { Respiratory infection } \\
\qquad(\mathrm{n}=380)\end{array}$ & $P$-value \\
\hline \multicolumn{5}{|c|}{ Sepsis syndromes at any time during the ICU stay } \\
\hline Severe sepsis & $449(82.8 \%)$ & $128(79.0 \%)$ & $321(84.5 \%)$ & 0.12 \\
\hline Septic shock & $241(44.5 \%)$ & $81(50.0 \%)$ & $160(42.1 \%)$ & 0.09 \\
\hline \multicolumn{5}{|l|}{ Procedures during ICU stay } \\
\hline Mechanical ventilation & $437(80.6 \%)$ & $129(79.6 \%)$ & $308(81.1 \%)$ & 0.70 \\
\hline Hemofiltration & $69(12.7 \%)$ & $29(17.9 \%)$ & $40(10.5 \%)$ & 0.02 \\
\hline Hemodialysis & $27(5.0 \%)$ & $8(4.9 \%)$ & $19(5.0 \%)$ & 0.97 \\
\hline \multicolumn{5}{|l|}{ SOFA scores } \\
\hline SOFA max & $8.4 \pm 4.4$ & $8.4 \pm 4.8$ & $8.4 \pm 4.3$ & 0.90 \\
\hline SOFA mean & $5.6 \pm 3.9$ & $5.6 \pm 4.0$ & $5.6 \pm 3.9$ & 0.95 \\
\hline \multicolumn{5}{|l|}{ Early organ failure ${ }^{a}$} \\
\hline Renal & $174(32.1 \%)$ & $62(38.3 \%)$ & $112(29.5 \%)$ & 0.04 \\
\hline Respiratory & $286(52.8 \%)$ & 79 (48.8\%) & $207(54.5 \%)$ & 0.22 \\
\hline Coagulation & $64(11.8 \%)$ & $28(17.3 \%)$ & $36(9.5 \%)$ & 0.01 \\
\hline Hepatic & $33(6.1 \%)$ & 7 (4.3\%) & $26(6.8 \%)$ & 0.26 \\
\hline CNS & $132(24.4 \%)$ & $16(9.9 \%)$ & $116(30.5 \%)$ & $<0.001$ \\
\hline Cardiovascular & $249(45.9 \%)$ & $90(55.6 \%)$ & $159(41.8 \%)$ & 0.003 \\
\hline \multicolumn{5}{|l|}{ Late organ failure } \\
\hline Renal & $74(13.7 \%)$ & 16 (9.9\%) & $58(15.3 \%)$ & 0.09 \\
\hline Respiratory & $56(10.3 \%)$ & 17 (10.5\%) & $39(10.3 \%)$ & 0.93 \\
\hline Coagulation & $16(3.0 \%)$ & 7 (4.3\%) & $9(2.4 \%)$ & 0.21 \\
\hline Hepatic & $16(3.0 \%)$ & $8(4.9 \%)$ & $8(2.1 \%)$ & 0.07 \\
\hline CNS & 27 (5.0\%) & $8(4.9 \%)$ & $19(5.0 \%)$ & 0.97 \\
\hline Cardiovascular & $30(5.5 \%)$ & $6(3.7 \%)$ & $24(6.3 \%)$ & 0.22 \\
\hline \multicolumn{5}{|l|}{ Organ failure any time } \\
\hline Renal & $248(45.8 \%)$ & $78(48.1 \%)$ & $170(44.7 \%)$ & 0.46 \\
\hline Respiratory & $342(63.1 \%)$ & $96(59.3 \%)$ & $246(64.7 \%)$ & 0.22 \\
\hline Coagulation & $80(14.8 \%)$ & $35(21.6 \%)$ & $45(11.8 \%)$ & 0.003 \\
\hline Hepatic & 49 (9.0\%) & 15 (9.3\%) & $34(8.9 \%)$ & 0.90 \\
\hline CNS & $159(29.3 \%)$ & $24(14.8 \%)$ & $135(35.5 \%)$ & $<0.001$ \\
\hline Cardiovascular & 279 (51.5\%) & 96 (59.3\%) & 183 (48.2\%) & 0.01 \\
\hline
\end{tabular}

CNS: Central nervous system; ${ }^{a}$, occurring within 48 hours of a diagnosis of sepsis;

b, occurring more than 48 hours after a diagnosis of sepsis

secondary nosocomial infection. The presence of secondary infections is associated with an increased length of stay [29], but the effect of secondary infections on mortality is controversial, because patients who develop secondary infections are generally sicker and more likely to die $[2-7,27,30]$.

Interestingly, there were no differences in ICU (29\%) or hospital (38\%) mortality between the two groups despite the greater incidence of septic shock on admission in patients with abdominal infections. Mortality rates in studies of infection and sepsis in the ICU are quite variable. In studies in surgical ICUs, ICU mortality rates in patients with abdominal infections varied from $22 \%$ to $72 \%$ [13-15,28,31-33]. ICU mortality rates for patients with community-acquired pneumonia range from $32 \%$ to $49 \%$ [22,34-36], and are perhaps higher in patients with hospital-acquired pneumonia [37].

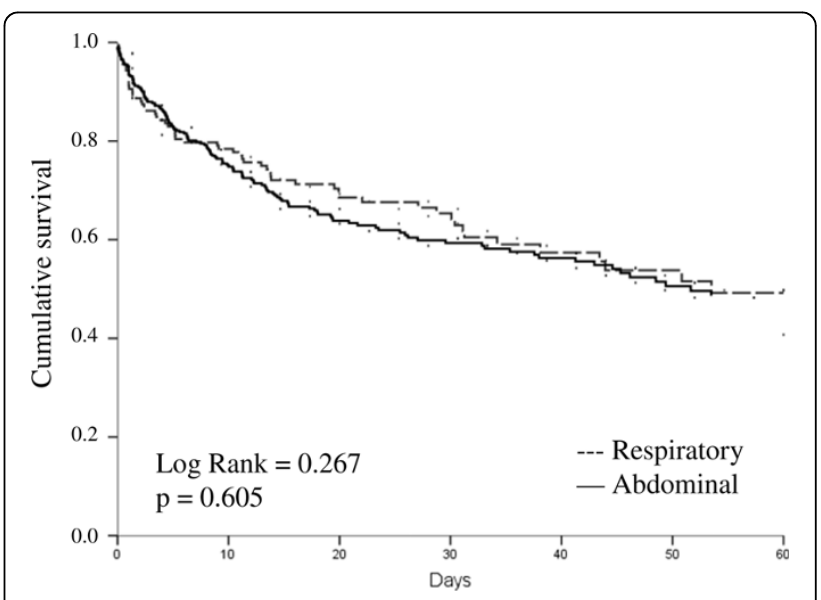

Figure 2 Kaplan-Meier survival curves representing 60-day survival in patients with respiratory and those with abdominal infection. Log Rank $=0.267: P=0.605$. 
Table 6 Summary of Cox proportional hazard regression analysis with hospital mortality as the dependent variable

\begin{tabular}{|c|c|c|c|c|}
\hline & Estimated coefficient & SE & Hazard ratio $(95 \% \mathrm{Cl})$ & $P$-value \\
\hline Age, per year & 0.04 & 0.01 & 1.04 (1.03 to 1.05$)$ & $<0.001$ \\
\hline Cancer & 0.57 & 0.20 & 1.76 (1.20 to 2.59$)$ & 0.004 \\
\hline Septic shock on admission & 0.42 & 0.15 & 1.52 (1.13 to 2.04$)$ & 0.006 \\
\hline Early coagulation failure & 0.98 & 0.18 & 2.68 (1.88 to 3.80$)$ & $<0.001$ \\
\hline Early acute renal failure & 0.6 & 0.15 & 1.83 (1.37 to 2.45$)$ & $<0.001$ \\
\hline Early neurological failure & 0.36 & 0.16 & $1.43(1.04$ to 1.96$)$ & 0.029 \\
\hline \multicolumn{5}{|c|}{ Abdominal/respiratory variable } \\
\hline Respiratory infection & \multicolumn{4}{|c|}{ reference } \\
\hline Abdominal infection & 0.28 & 0.19 & $1.32(0.91$ to 1.92$)$ & 0.149 \\
\hline
\end{tabular}

Cl: confidence interval; SE: standard error of the estimate

Malacarne and colleagues found that among different sites of infection, only peritonitis diagnosed during the ICU stay was an independent prognostic factor for hospital mortality (OR 3.4, $P=0.0021$ ) [4]. Although in our study, ICU lengths of stay were similar, the hospital length of stay was longer in patients with abdominal infection than in those with respiratory infection. We can speculate that this may be due to differences in baseline characteristics and the surgical nature of abdominal infections which can require more prolonged periods for resolution.

The advantage of our study is that it involves a large database from multiple centers with systematic collection of data. One limitation of the study is that the diagnoses of abdominal and respiratory infections were made at the discretion of the attending physician and criteria may have varied slightly from one center to another. As part of an observational study with a waiver of informed consent, we were unable to perform invasive tests to obtain more specific diagnoses and had to rely on what was routine clinical practice in the participating centers. In addition, we were unable to distinguish between hospitaland community-acquired infections. Moreover, septic shock was defined as the presence of infection plus the need for vasopressor agents, according to standard criteria at the time of the study. However, particularly in surgical patients, vasopressors may be required as a result of anesthetic agents, epidural anesthesia, blood loss, and so on, so that in the presence of infection it may be difficult to accurately distinguish the specific reason for vasopressor agents, thus confounding the diagnosis. Moreover, there were some differences in patient characteristics among the two groups of patients, but the multivariate analysis we performed adjusted for a large number of these and other variables which are known to influence outcome prediction.

\section{Conclusions}

This analysis revealed that the two most common sources of infection on admission to the ICU are associated with different profiles. Patients with abdominal infection on admission are more likely to have septic shock on admission and to have early renal and coagulation failure, whereas patients with respiratory infection more commonly have early alteration in neurological function. The length of hospital stay in patients with abdominal infection is longer, likely because of the increased numbers of secondary infections in these patients. However, mortality rates were identical in the two groups of patients. These observations outline interesting differences depending on the source of sepsis, which may have important implications for our understanding of the epidemiology of sepsis and in the conduct of clinical trials.

\section{Key messages}

- ICU patients admitted with abdominal infections have different profiles compared to those admitted with respiratory infections.

- ICU patients admitted with abdominal infections had longer hospital lengths of stay and increased numbers of secondary infections compared to patients admitted with respiratory infections.

- However, ICU and hospital mortality rates were the same regardless of the source of sepsis.

Additional file 1: Participants by country (listed alphabetically). A

Word file containing a list of participants by country, in alphabetical order.

\section{Abbreviations}

AIDS: acquired immunodeficiency syndrome; CNS: central nervous syndrome; COPD: chronic obstructive pulmonary disease; CSF: cerebrospinal fluid; ER: emergency room; ICU: intensive care unit; MRSA: methicillin-resistant Staphylococcus aureus; OR: operating room; SAPS: simplified acute physiology score; SOAP: Sepsis in Acutely ill Patients; SOFA: sequential organ failure assessment; SPSS: Statistical Package for SocialSciences.

\section{Acknowledgements}

The SOAP study was supported by an unlimited grant from Abbott, Baxter, Eli Lilly, GlaxoSmithKline, and NovoNordisk. These companies had no involvement at any stage of the study design, in the collection and analysis 
of data, in writing the manuscript, or in the decision to submit for publication.

\section{Author details}

${ }^{1}$ Dept of Intensive Care, Erasme Hospital, Université Libre de Bruxelles, Route de lennik 808, 1070 Brussels, Belgium. ${ }^{2}$ Dept of Anesthesiology and Intensive Care Medicine, Campus Virchow-Klinikum and Campus Charité Mitte, Hindenburgdamm 30, D-12200 Berlin, Germany. ${ }^{3}$ Intensive Care Unit, Henry Dunant Hospital, Department of Medicine, 107 Mesogion Av, 11526 Athens, Greece. ${ }^{4}$ Dept of Intensive Care, Institute for Cardiovascular Research, VU University Medical Center, De Boelelaan 1117, 1081 Amsterdam, The Netherlands. ${ }^{5}$ Dept of Anesthesiology and Intensive Care, Friedrich-Schiller University, Erlanger Allee 101, D-07747 Jena, Germany.

\section{Authors' contributions}

JLV conceived the initial SOAP study. EV, CS, AM, JG, YS and JLV participated in the design and coordination of the SOAP study. YS performed the statistical analyses. EV and JLV drafted the present manuscript. All authors read and approved the final manuscript.

\section{Competing interests}

The authors declare that they have no competing interests.

Received: 11 January 2010 Revised: 26 February 2010

Accepted: 15 March 2010 Published: 15 March 2010

\section{References}

1. Vincent JL, Rello J, Marshall J, Silva E, Anzueto A, Martin CD, Moreno R, Lipman J, Gomersall C, Sakr Y, Reinhart K, EPIC II Groups of Investigators: International study of the prevalence and outcomes of infection in intensive care units. JAMA 2009, 302:2323-2329.

2. Ponce de Leon-Rosales SP, Molinar-Ramos F, Dominguez-Cherit G, RangelFrausto MS, Vazquez-Ramos VG: Prevalence of infections in intensive care units in Mexico: a multicenter study. Crit Care Med 2000, 28:1316-1321.

3. Alberti C, Brun-Buisson C, Burchardi H, Martin C, Goodman S, Artigas A, Sicignano A, Palazzo M, Moreno R, Boulme R, Lepage E, Le Gall R: Epidemiology of sepsis and infection in ICU patients from an international multicentre cohort study. Intensive Care Med 2002, 28:108-121.

4. Malacarne P, Langer M, Nascimben E, Moro ML, Giudici D, Lampati L, Bertolini G: Building a continuous multicenter infection surveillance system in the intensive care unit: findings from the initial data set of 9,493 patients from 71 Italian intensive care units. Crit Care Med 2008, 36:1105-1113.

5. Ylipalosaari P, Ala-Kokko TI, Laurila J, Ohtonen P, Syrjala H: Community- and hospital-acquired infections necessitating ICU admission: spectrum, comorbidities and outcome. J Infect 2006, 53:85-92.

6. Vincent JL, Sakr Y, Sprung CL, Ranieri VM, Reinhart K, Gerlach H, Moreno R, Carlet J, Le Gall JR, Payen D: Sepsis in European intensive care units: results of the SOAP study. Crit Care Med 2006, 34:344-353.

7. Fagon JY, Novara A, Stephan F, Girou E, Safar M: Mortality attributable to nosocomial infections in the ICU. Infect Control Hosp Epidemiol 1994, 15:428-434.

8. Laupland KB, Zygun DA, Davies HD, Church DL, Louie TJ, Doig CJ: Incidence and risk factors for acquiring nosocomial urinary tract infection in the critically ill. J Crit Care 2002, 17:50-57.

9. Rosenthal VD, Guzman S, Orellano PW: Nosocomial infections in medicalsurgical intensive care units in Argentina: attributable mortality and length of stay. Am J Infect Control 2003, 31:291-295.

10. Guidet B, Aegerter P, Gauzit R, Meshaka P, Dreyfuss D: Incidence and impact of organ dysfunctions associated with sepsis. Chest 2005, 127:942-951.

11. Finfer S, Bellomo R, Lipman J, French C, Dobb G, Myburgh J: Adultpopulation incidence of severe sepsis in Australian and New Zealand intensive care units. Intensive Care Med 2004, 30:589-596.

12. Valles J, Rello J, Ochagavia A, Garnacho J, Alcala MA: Community-acquired bloodstream infection in critically ill adult patients: impact of shock and inappropriate antibiotic therapy on survival. Chest 2003, 123:1615-1624.

13. Weiss G, Steffanie W, Lippert H: [Peritonitis: main reason of severe sepsis in surgical intensive care]. Zentralb/ Chir 2007, 132:130-137.
14. Barie PS, Hydo LJ, Eachempati SR: Longitudinal outcomes of intraabdominal infection complicated by critical illness. Surg Infect (Larchmt) 2004, 5:365-373.

15. De Waele JJ, Hoste EA, Blot Sl: Blood stream infections of abdominal origin in the intensive care unit: characteristics and determinants of death. Surg Infect (Larchmt) 2008, 9:171-177

16. Le Gall JR, Lemeshow S, Saulnier F: A new Simplified Acute Physiology Score (SAPS II) based on a European/North American multicenter study. JAMA 1993, 270:2957-2963.

17. Vincent JL, de Mendonca A, Cantraine F, Moreno R, Takala J, Suter PM, Sprung $\mathrm{CL}$, Colardyn F, Blecher S: Use of the SOFA score to assess the incidence of organ dysfunction/failure in intensive care units: results of a multicenter, prospective study. Working group on "sepsis-related problems" of the European Society of Intensive Care Medicine. Crit Care Med 1998, 26:1793-1800

18. Bone RC, Balk RA, Cerra FB, Dellinger RP, Fein AM, Knaus WA, Schein RM, Sibbald WJ: Definitions for sepsis and organ failure and guidelines for the use of innovative therapies in sepsis. The ACCP/SCCM Consensus Conference Committee. American College of Chest Physicians/Society of Critical Care Medicine. Chest 1992, 101:1644-1655.

19. Hosmer D, Lemeshow S: Applied Logistic Regression San Francisco: Wiley Interscience 2000 .

20. Adrie C, Alberti C, Chaix-Couturier C, Azoulay E, De Lassence A, Cohen Y, Meshaka P, Cheval C, Thuong M, Troche G, Garrouste-Orgeas M, Timsit JF: Epidemiology and economic evaluation of severe sepsis in France: age, severity, infection site, and place of acquisition (community, hospital, or intensive care unit) as determinants of workload and cost. J Crit Care 2005, 20:46-58

21. Leroy O, Vandenbussche C, Coffinier C, Bosquet C, Georges H, Guery B, Thevenin D, Beaucaire G: Community-acquired aspiration pneumonia in intensive care units. Epidemiological and prognosis data. Am J Respir Crit Care Med 1997, 156:1922-1929.

22. Tejerina E, Frutos-Vivar F, Restrepo Ml, Anzueto A, Palizas F, Gonzalez M, Apezteguia C, Abroug F, Matamis D, Bugedo G, Esteban A: Prognosis factors and outcome of community-acquired pneumonia needing mechanical ventilation. J Crit Care 2005, 20:230-238

23. Cardoso TC, Lopes LM, Carneiro AH: A case-control study on risk factors for early-onset respiratory tract infection in patients admitted in ICU. BMC Pulm Med 2007, 7:12.

24. Levi M: The coagulant response in sepsis. Clin Chest Med 2008, 29:627-642.

25. Bottiger BW, Snyder-Ramos SA, Lapp W, Motsch J, Aulmann M, Schweizer M, Layug EL, Martin E, Mangano DT: Association between early postoperative coagulation activation and peri-operative myocardial ischaemia in patients undergoing vascular surgery. Anaesthesia 2005, 60:1162-1167.

26. Boldt J, Huttner I, Suttner S, Kumle B, Piper SN, Berchthold G: Changes of haemostasis in patients undergoing major abdominal surgery-is there a difference between elderly and younger patients?. Br J Anaesth 2001, 87:435-440.

27. Agarwal R, Gupta D, Ray P, Aggarwal AN, Jindal SK: Epidemiology, risk factors and outcome of nosocomial infections in a respiratory intensive care unit in North India. J Infect 2006, 53:98-105.

28. Merlino Jl, Yowler CJ, Malangoni MA: Nosocomial infections adversely affect the outcomes of patients with serious intraabdominal infections. Surg Infect (Larchmt) 2004, 5:21-27.

29. Olaechea PM, Ulibarrena MA, Alvarez-Lerma F, Insausti J, Palomar M, De la Cal MA, ENVIN-UCI Study Group: Factors related to hospital stay among patients with nosocomial infection acquired in the intensive care unit. Infect Control Hosp Epidemiol 2003, 24:207-213.

30. Damas $P$, Ledoux D, Nys M, Monchi M, Wiesen P, Beauve B, Preiser JC: Intensive care unit acquired infection and organ failure. Intensive Care Med 2008, 34:856-864.

31. Schoenberg MH, Weiss M, Radermacher P: Outcome of patients with sepsis and septic shock after ICU treatment. Langenbecks Arch Surg 1998 383:44-48

32. Marshall JC, Innes M: Intensive care unit management of intra-abdominal infection. Crit Care Med 2003, 31:2228-2237.

33. Markogiannakis $H$, Pachylaki N, Samara E, Kalderi M, Minettou M Toutouza M, Toutouzas KG, Theodorou D, Katsaragakis S: Infections in a surgical intensive care unit of a university hospital in Greece. Int J Infect Dis 2009, 13:145-153 
34. Yoshimoto A, Nakamura H, Fujimura M, Nakao S: Severe communityacquired pneumonia in an intensive care unit: risk factors for mortality. Intern Med 2005, 44:710-716.

35. Woodhead M, Welch CA, Harrison DA, Bellingan G, Ayres JG: Communityacquired pneumonia on the intensive care unit: secondary analysis of 17,869 cases in the ICNARC Case Mix Programme Database. Crit Care 2006, 10:S1.

36. Lee JH, Ryu YJ, Chun EM, Chang JH: Outcomes and prognostic factors for severe community-acquired pneumonia that requires mechanical ventilation. Korean J Intern Med 2007, 22:157-163.

37. Valles J, Mesalles E, Mariscal D, del Mar FM, Pena R, Jimenez JL, Rello J: A 7year study of severe hospital-acquired pneumonia requiring ICU admission. Intensive Care Med 2003, 29:1981-1988.

doi:10.1186/cc8909

Cite this article as: Volakli et al:: Infections of respiratory or abdominal origin in ICU patients: what are the differences?. Critical Care 2010 14: R32.

\section{Submit your next manuscript to BioMed Central} and take full advantage of:

- Convenient online submission

- Thorough peer review

- No space constraints or color figure charges

- Immediate publication on acceptance

- Inclusion in PubMed, CAS, Scopus and Google Scholar

- Research which is freely available for redistribution

Submit your manuscript at www.biomedcentral.com/submit 